\title{
Electrochemical uranyl biosensor with DNA oligonucleotides as receptor layer
}

\author{
Robert Ziólkowski • Lukasz Górski • \\ Sławomir Oszwałdowski • Elżbieta Malinowska
}

Received: 6 July 2011 /Revised: 6 September 2011 / Accepted: 17 October 2011 / Published online: 8 November 2011

(C) The Author(s) 2011. This article is published with open access at Springerlink.com

\begin{abstract}
The feasibility of using gold electrodes modified with short-chain ssDNA oligonucleotides for determination of uranyl cation is examined. Interaction between $\mathrm{UO}_{2}{ }^{2+}$ and proposed recognition layer was studied by means of voltammetric and quartz crystal microbalance measurements. It was postulated that ssDNA recognition layer functions via strong binding of $\mathrm{UO}_{2}{ }^{2+}$ to phosphate DNA backbone. The methylene blue was used as a redox marker for analytical signal generation. Biosensor response was based on the difference in electrochemical signal before and after subjecting it to sample containing uranyl ion. The lower detection limit of $30 \mathrm{nmol} \mathrm{L} \mathrm{L}^{-1}$ for $\mathrm{UO}_{2}{ }^{2+}$ was observed for a sample incubation time of $60 \mathrm{~min}$. Proposed ssDNA-modified electrodes demonstrated good selectivity towards $\mathrm{UO}_{2}{ }^{2+}$ against common metal cations, with only $\mathrm{Pb}^{2+}$ and $\mathrm{Ca}^{2+}$ showing considerable interfering effect.
\end{abstract}

Keywords Biosensors · Electroanalytical methods . Electrochemical sensors · Mass sensitive sensors · Stripping analysis

Published in the special issue Analytical and Bioanalytical Science in Poland with guest editor Marek Biziuk.

R. Ziółkowski • Ł. Górski $(\bowtie) \cdot$ E. Malinowska

Institute of Biotechnology, Department of Microbioanalytics,

Faculty of Chemistry, Warsaw University of Technology,

Noakowskiego 3,

00-664 Warsaw, Poland

e-mail: lukegor@ch.pw.edu.pl

S. Oszwałdowski

Department of Analytical Chemistry, Faculty of Chemistry,

Warsaw University of Technology,

Noakowskiego 3,

00-664 Warsaw, Poland

\section{Introduction}

Uranium and its compounds are used as nuclear power plants fuel, for the production of tanks armor and armorpiercing ammunition, for staining of ceramic products, as well as for electron microscopy investigations of biological samples [1]. All of these applications can possibly be hazardous to human health or environment. That is why rapid and accurate methods allowing for detection of trace levels of uranyl ion in environmental, geochemical or clinical samples are indispensable.

Uranium occurs mainly in two valence states, $\mathrm{U}^{4+}$ and $\mathrm{U}^{6+}$, with the latter forming water-soluble uranyl ion $\left(\mathrm{UO}_{2}{ }^{2+}\right)$ compounds. The uranium species in aqueous samples were determined using a variety of physical and chemical techniques, with radiospectrometry [2], inductively coupled plasma mass spectrometry [3] and complexometric titration [4] being the most popular. However, all of these techniques require utilization of costly and complicated apparatus. On the other hand, electroanalytical techniques are very useful due to their operation simplicity, low utilization costs, and the possibility of achieving extremely low detection limits.

The most commonly used electrochemical method for determination of uranyl ion at low levels is adsorptive stripping voltammetry [5-7]. The preconcentration and subsequent analysis allows obtaining detection limit of $2 \cdot 10^{-8} \mathrm{~mol} \mathrm{~L}^{-1}$ [5]. To further improve the selectivity and the lower detection limit, a range of complexing reagents was introduced. These ligands form complexes with uranyl cation with increased adherence to the electrode surface. Some of the compounds used for this purpose are: 2thenoyltrifluoroacetone-tributylphosphine oxide (detection limit, $10^{-10} \mathrm{~mol} \mathrm{~L}^{-1}$ ) [4], cupferron (detection limit, $3.7 \cdot 10^{-10} \mathrm{~mol} \mathrm{~L}^{-1}$ ) [8], or 2,6-pyridinedicarboxylic acid (detection limit, $0.27 \cdot 10^{-9} \mathrm{~mol} \mathrm{~L}^{-1}$ ) [9]. 
It has also been shown that uranyl cation has a strong affinity to phosphate residues [10]. This mechanism was used in various electrochemical sensors for uranyl ion determination with voltammetric or potentiometric transduction. In the case of voltammetric sensors, the recognition layer is deposited on the electrode. Some of the compounds used for such modification are as follows: 2-mercaptoethanol/ $\mathrm{POCl}_{3}$, cysteamine/2-aminoethyl dihydrogen phosphate, or (t-butylphenyl)- $N, N$-di-(isobutyl) carbamoylmethylphosphineoxide [11-13]. The uranyl ion detection limit for the last of abovementioned sensors is at parts per million level. Nevertheless, the analytical procedure in this case was very complicated. The same interaction was also used for the development of potentiometric sensors. PVC membranes containing bis $\{\mathrm{di}[4-(1,1,3,3$-tetramethylbutyl)phenyl] phosphate\} or bis(didecyl phosphate) salt as the electroactive components gave near-Nernstian uranyl calibration slopes and selectivity with selectivity coefficients $\left(K_{\mathrm{UO}_{2}^{2+}, \mathrm{Y}}^{\mathrm{pot}}\right)$ ranging from $9 \cdot 10^{-3}$ to $9 \cdot 10^{-4}$ [14]. It should be also mentioned that $\mathrm{UO}_{2}{ }^{2+}$ phosphate interaction was utilized for detection of phosphate ions using electrodes with polymeric membranes containing various uranyl salophene complexes as ionophores [15].

Since the early 1990s, nucleic acids were employed in detection of different chemical compounds $[16,17]$. This is possible due to discovery of catalytic and regulatory activities of nucleic acids, which opened completely new fields of their applications. These nucleic acid molecules are called functional nucleic acids - a term that covers DNA and RNA sequences which can act as enzymes, recognition elements, or molecular switches. Ribozymes, microRNAs, or riboswitches are naturally occurring functional RNA oligonucleotides. Nevertheless, there is also a broad range of artificial oligonucleotides representing similar properties. Depending on their acting mechanism, they are called aptamers, deoxyribozymes (DNAzymes), or allosteric nucleic acid enzymes. Such receptors were used for a detection of whole cells (e.g., Escherichia coli), small and large peptides (e.g., thrombin and $\operatorname{IgE}$ ) as well as different organic and inorganic compounds (e.g., adenosine, cocaine, AMP, neomycin, $\mathrm{K}^{+}, \mathrm{UO}_{2}{ }^{2+}$, and $\mathrm{Hg}^{2+}$ ). Electrochemical and optical measurements are the most common detection techniques utilized in combination with abovementioned receptor molecules [18].

In recent years, assays dedicated to uranyl ion detection employing DNAzymes were developed [19, 20]. The reported detection limit $\left(1 \mathrm{nmol} \mathrm{L}^{-1}\right)$ was below the uranium ion concentration level in marine waters. Moreover, the detection range was $1-700 \mathrm{nmol} \mathrm{L}^{-1}$ (in the case of label-free sensor) or $50 \mathrm{nmol} \mathrm{L}^{-1}-2 \mu \mathrm{mol} \mathrm{L}^{-1}$ (for labeled sensor). Nevertheless, as the mechanism of the detection is based on the cleavage of oligonucleotide strand and subsequent disassembly of AuNP aggregates at certain temperature, the whole system is sensitive to temperature and ionic strength changes. Additionally, the results also can be influenced by the changes in liquid turbidity [20].

Herein, we report that recognition layer of short DNA oligonucleotides, formed on gold electrode, can be useful for electrochemical uranyl ion detection. Uranyl cation interacts with phosphate DNA backbone, changing the electrostatic balance at the electrode surface [21]. These changes can be directly quantified with the use of redox marker. It is shown that this approach allows for the determination of uranyl ion at the trace level.

\section{Experimental}

\section{Apparatus}

Electrochemical measurements were conducted with a $\mathrm{CHI}$ $660 \mathrm{~A}$ electrochemical workstation (CH Instruments, USA). Voltammetric experiments were carried out with a threeelectrode system consisting of gold disk working electrode (CH Instruments, USA), a gold wire auxiliary electrode and an $\mathrm{Ag} / \mathrm{AgCl} / 1.0 \mathrm{~mol} \mathrm{~L}^{-1} \mathrm{KCl}$ reference electrode (Mineral, Poland). All potentials are reported versus $\mathrm{Ag} / \mathrm{AgCl}$ reference electrode at room temperature. To restore the gold electrode surface, the electrode polishing kit with alumina powder of different grain sizes was used. The electrochemical solutions were deoxygenated with argon for approximately $15 \mathrm{~min}$ prior to data acquisition and were blanketed under an argon atmosphere during the entire experimental period. If not stated otherwise, the cyclic voltammetry (CV) was conducted at a sweep rate of $100 \mathrm{mV} \mathrm{s}^{-1}$ while the square wave voltammetry was conducted at a pulse amplitude of $50 \mathrm{mV}$, increment of $1 \mathrm{mV}$, and a frequency of $10 \mathrm{~Hz}$.

The quartz crystal microbalance with energy dissipation (QCM-D) measurements were conducted with Q-Sense E4 instrument and the AT-cut quartz crystal with a fundamental resonant frequency of $4.95 \mathrm{MHz}$ and crystal constant of $17.7 \mathrm{ng} / \mathrm{cm}^{2} \mathrm{~Hz}^{-1}$ (Q-Sense, Sweden). The effective area of gold sensor exposed to solution is $0.78 \mathrm{~cm}^{2}$ with a roughness of less than $3 \mathrm{~nm}$. Such an assay allows to measure the change in frequency and energy dissipation which, with the use of a Voigt-based representation, can be converted into the mass deposited on the gold surface.

For capillary electrophoresis experiments, system with ultraviolet-visible (UV-Vis) detector (Prince Technologies, the Netherlands) and a fused-silica capillary (50 $\mu \mathrm{m}$ (i.d.), $375 \mu \mathrm{m}$ (o.d.), $x \mathrm{~cm}$ long, $y \mathrm{~cm}$ effective length, $x / y=82 / 65$; Composite Metal, England) was applied. Prior to the daily use, the capillary was pretreated by flushing sequentially for 15 min with $0.1 \mathrm{~mol} \mathrm{~L}^{-1} \mathrm{NaOH}, 5$ min with water, and 5 min with run buffer. The capillary was also rinsed with 
$0.1 \mathrm{~mol} \mathrm{~L}^{-1} \mathrm{NaOH}$ (5 min), water $(3 \mathrm{~min})$, and buffer ( $5 \mathrm{~min}$ ) after each run. Samples were separated using micellar electrolyte buffer containing surfactant $\left(50 \mathrm{mmol} \mathrm{L}^{-1} \mathrm{SDS}\right)$, $25 \mathrm{mmol} \mathrm{L}^{-1}$ sodium tetraborate, and $50 \mathrm{mmol} \mathrm{L}^{-1}$ sodium phosphate monobasic. Injection was performed at $50 \mathrm{mbar}$ for $6 \mathrm{~s}$ from anode side. Applied voltage is $+20 \mathrm{kV}$; UV-Vis detection at 200 or $260 \mathrm{~nm}$.

\section{Reagents}

Reagent-grade $\mathrm{H}_{2} \mathrm{O}_{2}, \mathrm{H}_{2} \mathrm{SO}_{4}, \mathrm{KCl}, \mathrm{K}_{2} \mathrm{HPO}_{4}, \mathrm{KH}_{2} \mathrm{PO}_{4}$, $\mathrm{NaH}_{2} \mathrm{PO}_{4}, \mathrm{NaCl}, \mathrm{NaOH}, \mathrm{HCl}$, Tris- $\mathrm{HCl}, \mathrm{Na}_{2} \mathrm{~B}_{4} \mathrm{O}_{7} \cdot 10 \mathrm{H}_{2} \mathrm{O}$, methylene blue, and uranyl acetate were purchased from Aldrich Chemicals. Absolute ethanol, $\mathrm{H}_{2} \mathrm{O}_{2}$, and $\mathrm{H}_{2} \mathrm{SO}_{4}$ were purchased from POCh, Poland. All reagents were used without further purification. All solutions were prepared using Milli-Q water. Milli-Q water and all aqueous buffer solutions were sterilized using an autoclave. The 20-mer deoxyoligonucleotide was purchased from Genomed Sp. z o.o., Poland. The base sequence was as follows: thiolated DNA probe: 5'-SH- $\left(\mathrm{CH}_{2}\right) 6$-CGACTGTGAATTCGTAG CAG-3' (20-base probe sequence-A).

Oligonucleotide stock solution were prepared with $10 \mathrm{mmol} \mathrm{L}{ }^{-1}$ Tris- $\mathrm{HCl}(\mathrm{pH} 7.5)$ and stored in a $-20{ }^{\circ} \mathrm{C}$ freezer before use.

\section{Solutions}

The following solutions were prepared: piranha solution $\left(\mathrm{H}_{2} \mathrm{O}_{2} / \mathrm{H}_{2} \mathrm{SO}_{4} ; 3: 1\right)$, base piranha solution $\left(\mathrm{H}_{2} \mathrm{O}_{2} / \mathrm{H}_{2} \mathrm{O} /\right.$ $\left.\mathrm{NH}_{4} \mathrm{OH} ; 1: 5: 1\right)$, and immobilization buffer solution containing $1 \mathrm{~mol} \mathrm{~L}^{-1} \mathrm{KH}_{2} \mathrm{PO}_{4}$ (pH 4.5). The electrochemical measurements were conducted in $50 \mathrm{mmol} \mathrm{L}^{-1}$ Tris- $\mathrm{HCl}$ solution containing (if needed) $50 \mu \mathrm{mol} \mathrm{L}{ }^{-1}$ methylene blue and/or uranyl acetate.

\section{Methods}

The interactions between oligonucleotides and uranyl cation were investigated electrochemically and with the use of QCM-D.

Before any voltammetric experiments, the gold electrode was polished successively with alumina powder of grain sizes from 1 to $0.05 \mu \mathrm{m}$. Then the electrode was washed with water and sonicated for $15 \mathrm{~min}$ in demineralized water. Next, the piranha solution was dropped on the working gold disk electrode and incubated for $30 \mathrm{~s}$. After removing this solution, the electrode was again washed with demineralized water. The last step of electrode preparation was its voltammetric cycling in $50 \mathrm{mmol} \mathrm{L}^{-1}$ Tris $-\mathrm{HCl}$ solution ( $\mathrm{pH} 3.0$ ), until the $\mathrm{CV}$ characteristic for a clean gold was obtained.
The DNA recognition monolayer was prepared as described in [22]. Briefly, after the electrode cleaning, the $4 \mu \mathrm{mol} \mathrm{L}{ }^{-1}$ solution of thiolated ssDNA in $1 \mathrm{~mol} \mathrm{~L}^{-1}$ $\mathrm{KH}_{2} \mathrm{PO}_{4}$ ( $\mathrm{pH} 4.5$ ) was dropped on the gold working disk electrode. The ssDNA immobilization was carried out for $120 \mathrm{~min}$. Then the solution was removed and the electrode was washed with $1 \mathrm{~mol} \mathrm{~L}^{-1} \mathrm{KH}_{2} \mathrm{PO}_{4}$ (pH 4.5), and electrochemical experiments were performed. No diluent thiols (e.g., mercaptohexanol) were used for ssDNA monolayer preparation.

All QCM-D experiments dealing with immobilization and interactions of DNA with uranyl acetate were conducted using the same buffer solutions as in the case of electrochemical assays. Nevertheless, to clean the gold transducers applied in gravimetric experiments, the QCM sensors were subjected to base piranha solution treatment at $70{ }^{\circ} \mathrm{C}$ for $15 \mathrm{~min}$. The sensor was washed with abundant amount of water, absolute ethanol, and then dried under argon atmosphere before placing in flow cell of QCM-D instrument, where the ssDNA immobilization process as well as subsequent experiments was carried out. The medium flow was set at $0.2 \mathrm{~mL} \mathrm{~min}^{-1}$ [23].

\section{Results and discussion}

\section{Preliminary experiments}

In all experiments conducted in this study, a random 20base probe sequence was used. No significant effects of DNA sequence are expected, as $\mathrm{UO}_{2}{ }^{2+}$ cation interacts with DNA strand via phosphate groups, identical for all DNA bases.

To evaluate the existence of DNA-uranyl cation interactions, the QCM-D measurements were performed. After the gold transducer cleaning, it was placed in quartz crystal microbalance chamber and the analysis was started. At first (step 1, Fig. 1), the immobilization buffer was passed through the chamber until the baseline frequency was constant. Then (step 2, Fig. 1), the transducer was subjected to solution of $4 \mu \mathrm{mol} \mathrm{L}{ }^{-1}$ DNA oligonucleotide in immobilization buffer. The frequency dropped dramatically which corresponds to the single-stranded DNA immobilization on the transducer surface. During step 3 of QCM-D experiments, the immobilization buffer was passed through the chamber in order to wash out all oligonucleotides adsorbed on the gold surface. After completion of this step, the $4 \mu \mathrm{mol} \mathrm{L}{ }^{-1}$ mercaptohexanol solution in immobilization buffer was used to fill transducer surface unoccupied by ssDNA. This step (4, Fig. 1) allows also for elimination of unspecified uranyl-transducer surface interactions. To obtain a baseline for investigation of DNA-uranyl interactions, the immobilization buffer was passed through the 
Fig. 1 Changes in QCM frequency (black line) and dissipation (gray line) upon

immobilization of ssDNA (step 2), mercaptohexanol (step 3) on gold electrode and the interaction with uranyl ion/ascorbic acid with ssDNA (step 6). Delta sign oscillation frequency difference resulting from uranyl ion interactions with phosphate groups of ssDNA

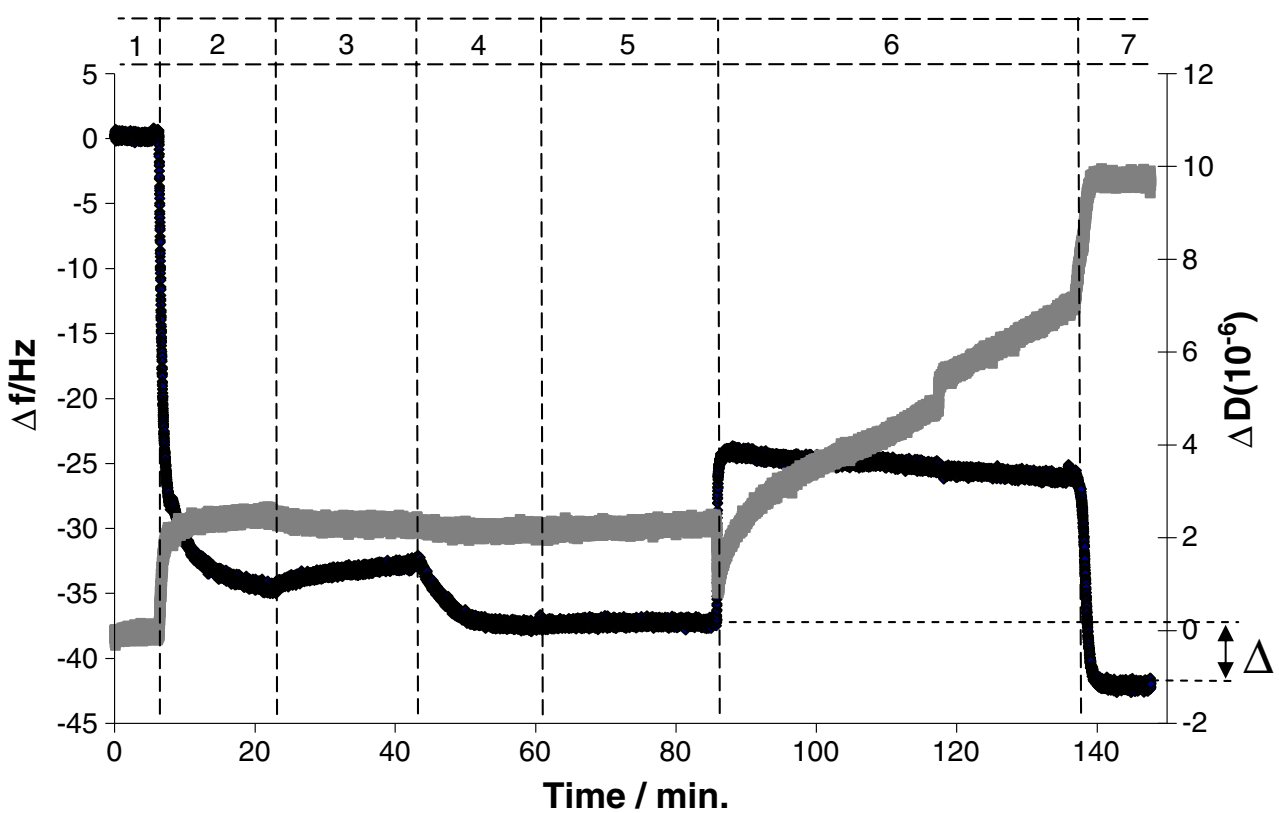

chamber (step 5, Fig. 1). Next, the solution of $1 \mathrm{mmol} \mathrm{L}^{-1}$ uranyl acetate and $1 \mathrm{mmol} \mathrm{L}^{-1}$ ascorbic acid in 50 mmol L ${ }^{-1}$ Tris- $\mathrm{HCl}(\mathrm{pH} 3.0)$ was introduced to QCM apparatus (step 6, Fig. 1). The instant frequency increase, observed at the beginning of this step, results from different energy losses at the liquid-crystal interface, corresponding
Fig. 2 Capillary electrophoresis of a $20 \mathrm{bp}$ oligonucleotide before subjection to ascorbic acid/ uranyl solution and c $20 \mathrm{bp}$ oligonucleotide after incubation in ascorbic acid/uranyl solution

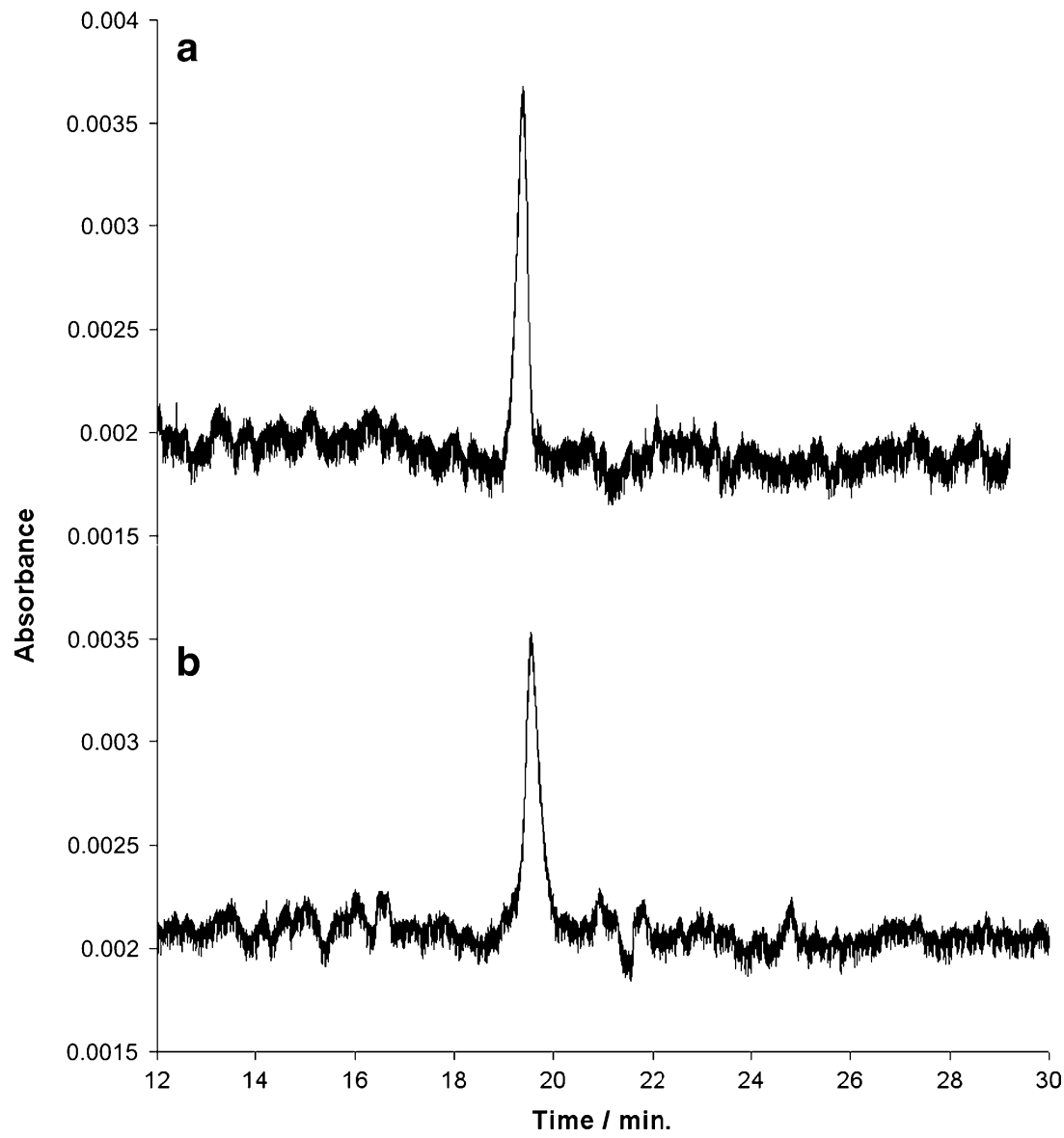




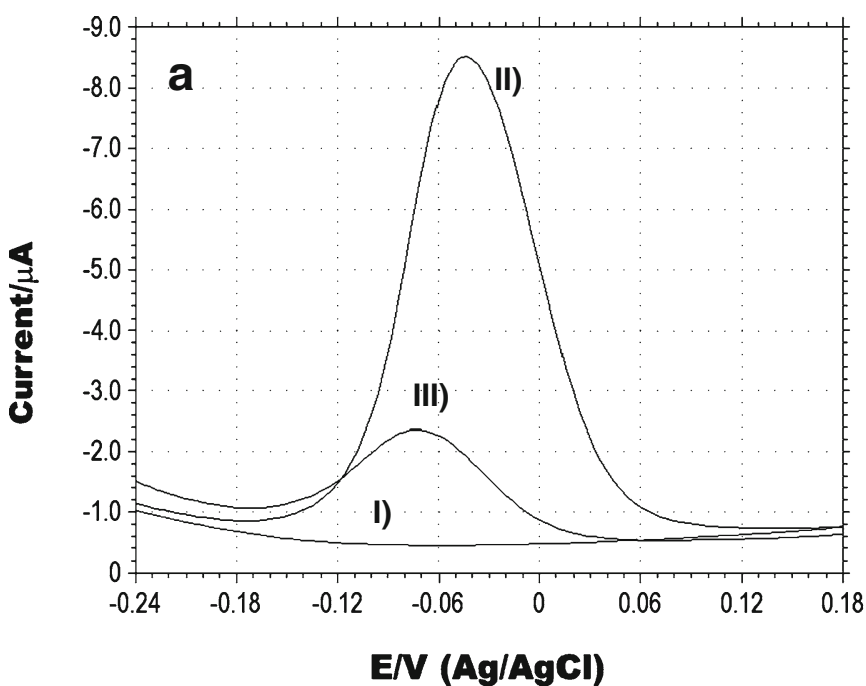

Fig. 3 Square wave voltammograms for gold disk electrode modified with ssDNA (a); unmodified electrode (b). (I) Analysis in $50 \mathrm{mmol} \mathrm{L} \mathrm{L}^{-1}$ Tris buffer solution, $\mathrm{pH}$ 3.0; (II) analysis in $50 \mathrm{mmol} \mathrm{L}{ }^{-1}$ Tris buffer solution, 3.0, containing $50 \mu \mathrm{mol} \mathrm{L} \mathrm{L}^{-1}$

to different medium composition [24]. Nevertheless, constant frequency decrease indicates the mass deposition at the transducer surface. This originates from the interactions of uranyl ions with phosphate moieties in DNA strand. In the last step of QCM measurements, the immobilization buffer was passed through the apparatus chamber (step 7, Fig. 1). The change of frequency, caused by the uranyl cation deposited at the transducer modified with oligonucleotide monolayer, is indicated by delta sign in Fig. 1.

Another important issue that had to be addressed before the construction of DNA-based uranyl sensor was the stability of receptor layer in the presence of $\mathrm{UO}_{2}{ }^{2+}$. It was reported that in a presence of reductive compounds (e.g., ascorbic acid), uranyl ion can lead to DNA degradation [25]. Although the abovementioned phenomena was reported for double-stranded long deoxyribonucleic acids, it is crucial to investigate the possibility of similar phenomenon in the case of single-stranded 20-mer oligonucleotide which will be used as receptor layer in this work. Based on the results shown in Fig. 1, cleaving effect is not evident, although these observations are not conclusive. To further explore this problem, capillary electrophoresis investigations were carried out [26]. As it can be seen in Fig. 2a, electropherogram of 20-mer oligonucleotide shows only one well-developed peak. To evaluate the influence of uranyl acetate solution (in combination with ascorbic acid) on tested oligonucleotide, samples containing $1 \mathrm{mmol} \mathrm{L}{ }^{-1}$

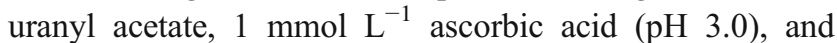
$4 \mu \mathrm{mol} \mathrm{L}{ }^{-1}$ of 20 -mer ssDNA were prepared. After $1 \mathrm{~h}$ of incubation, no distinct changes in retention time, peak height and area were observed (Fig. 2b). These results

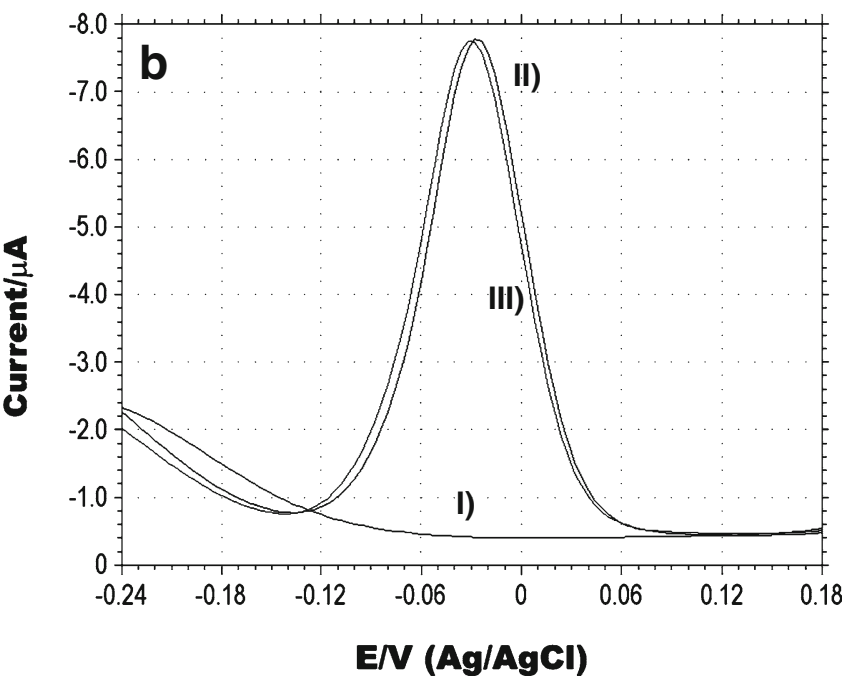

methylene blue; (III) analysis in $50 \mathrm{mmol} \mathrm{L}^{-1}$ Tris buffer solution, $\mathrm{pH} 3.0$, containing $50 \mu \mathrm{mol} \mathrm{L}-1$ methylene blue and $1 \mathrm{mmol} \mathrm{L}^{-1}$ uranyl acetate

definitely excluded the possibility of receptor layer degradation during $\mathrm{UO}_{2}{ }^{2+}$ determination.
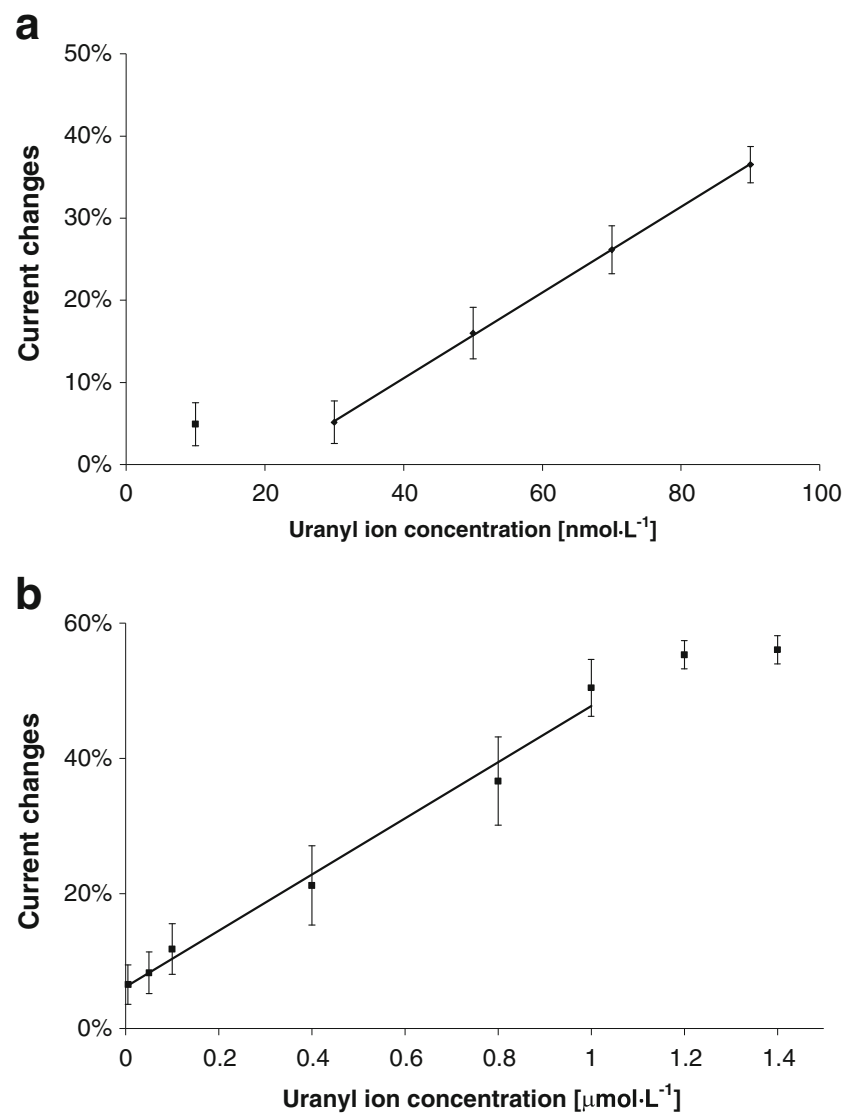

Fig. 4 Calibration curve towards uranyl acetate for ssDNA-modified electrode: a 60 and b 5 min incubation time. Each experiment was repeated three times with the use of the same electrode 
Fig. 5 DNA biosensor selectivity. Values at the $y$-axis are the differences between MB reduction signal before and after incubation of the electrode in $0.4 \mu \mathrm{mol} \mathrm{L}{ }^{-1}$ solution of appropriate cation

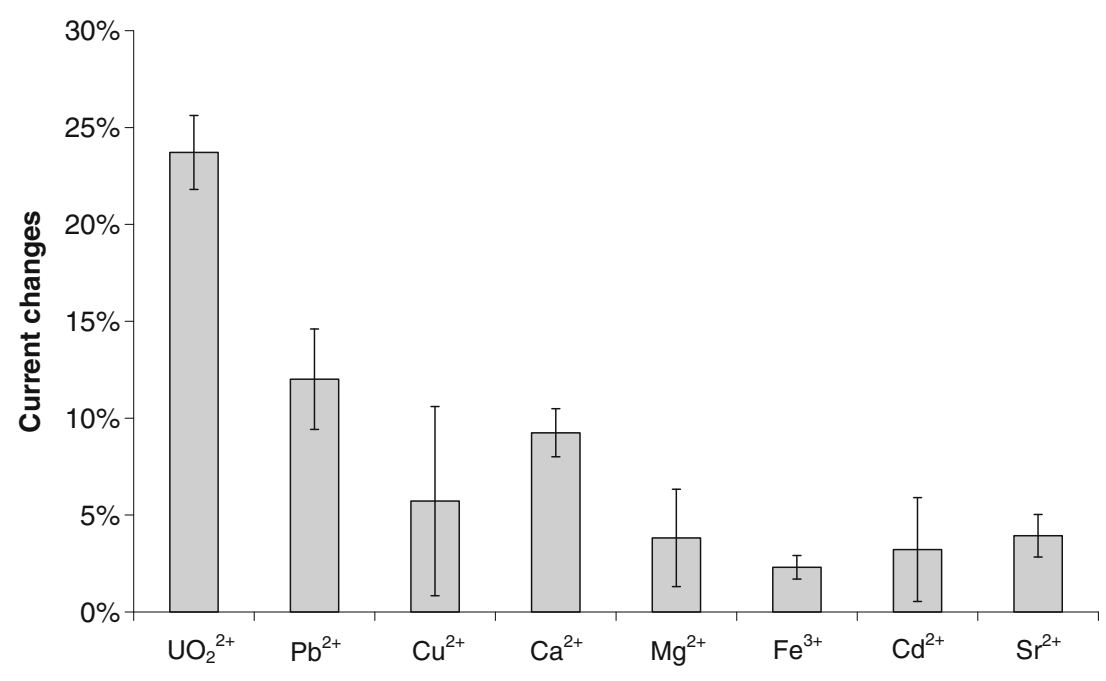

Electrochemical investigations

First, electrochemical measurements were conducted without any external redox marker, relaying on the redox properties of $\mathrm{UO}_{2}{ }^{2+}$ ion. However, these experiments were not successful, as current signal, registered for ssDNAmodified electrode in uranyl acetate solution, was about five times lower, as compared with unmodified $\mathrm{Au}$ electrode (data not shown). It seems that the electron and mass transfer is limited by ssDNA immobilized at the electrode surface.

For further investigations, a well described DNA redox label, methylene blue, was employed (it was not introduced in preliminary QCM experiments due to its low mass and resulting small frequency changes). The postulated mechanism of analytical signal generation is as follows: after subjection of DNA-modified gold electrode to uranyl acetate solution, the total negative charge of receptor layer decreases due to complexation of $\mathrm{UO}_{2}{ }^{2+}$ with DNA backbone phosphate groups. This weakens the interaction of cationic methylene blue with DNA receptor layer. As a consequence, methylene blue molecules are replaced by $\mathrm{UO}_{2}{ }^{2+}$ ion, allowing electrochemical determination of uranyl cation. Indeed, comparison of curves (II) and (III) in Fig. 3a reveals a dramatic drop in the measured current. Analogous voltammograms for bare gold electrode show almost identical current values registered for methylene blue solution with or without the presence of uranyl cation (Fig. 3b). Based on these results, it is evident that ssDNA immobilized on the electrode interacts with $\mathrm{UO}_{2}{ }^{2+}$. Significant change of analytical signal after the contact of receptor layer with analyte cation, encouraged us to utilize this mechanism for quantitative uranyl cation determination.

Further experiments were carried out in order to investigate the analytical parameters of proposed biosensors. As the proposed mechanism is based at the uranyl preconcentration at the electrode surface, the incubation time of $60 \mathrm{~min}$ was chosen. This was intended to saturate the oligonucleotide strands with analyte cation, namely $\mathrm{UO}_{2}{ }^{2+}$. To prepare the calibration curve, the difference in current peak surface for methylene blue before and after the contact of the proposed sensor with sample solutions was plotted against uranyl ion concentration.

As shown in Fig. 4a, the obtained lower detection limit (LDL) for $\mathrm{UO}_{2}{ }^{2+}$ was $30 \mathrm{nmol} \mathrm{L}{ }^{-1}$. Moreover, calibration curve has fairly high slope (5.216) and good linear correlation $\left(R^{2}=0.9998\right)$. The upper detection limit was slightly below $0.1 \mu \mathrm{mol} \mathrm{L}{ }^{-1}$, resulting in relatively narrow

Table 1 Comparison of chosen uranyl ion determination methods

\begin{tabular}{|c|c|c|c|c|c|}
\hline Technique & Analysis time (min) & Selectivity & $\operatorname{LDL}\left(\mathrm{mol} \mathrm{L}^{-1}\right)$ & Detection range $\left(\mathrm{mol} \mathrm{L}^{-1}\right)$ & Reference \\
\hline Adsorptive stripping voltammetry & 3 & ND & $2 \cdot 10^{-8}$ & ND & [5] \\
\hline Electrochemical sensor & 21 & ND & $1 \cdot 10^{-6}$ & $1-10 \cdot 10^{-6}$ & {$[11]$} \\
\hline Potentiometry & 0.35 & $9 \cdot 10^{-4}$ & $9 \cdot 10^{-2}$ & $9 \cdot 10^{-2}-10^{-5}$ & {$[14]$} \\
\hline Optical biosensor & 30 & Excellent & $50 \cdot 10^{-8}$ & $2 \cdot 10^{-6}-5 \cdot 10^{-7}$ & {$[20]$} \\
\hline Electrochemical biosensor & 6 & Good & $5 \cdot 10^{-8}$ & $1 \cdot 10^{-6}-5 \cdot 10^{-8}$ & This work \\
\hline
\end{tabular}


linear calibration range. This fact can be attributed to the saturation of ssDNA recognition layer with uranyl cations, which can be achieved even at very low $\mathrm{UO}_{2}{ }^{2+}$ concentration during long incubation time.

Despite very useful analytical parameters obtained for proposed sensors, long analysis time (60 $\mathrm{min})$ is inconvenient for everyday analytical practice. Accordingly, the next set of measurements was conducted with the 5-min incubation time. The linear response was recorded in the range of 0.05 to $1.0 \mu \mathrm{mol} \mathrm{L}{ }^{-1}$ uranyl ion concentration, with relatively low slope (0.416) and moderate correlation $\left(R^{2}=0.9873\right.$; Fig. $\left.4 \mathrm{~b}\right)$. In the case of higher $\mathrm{UO}_{2}{ }^{2+}$ concentration, the calibration curve flattens while for lower concentrations, observed signal decrease is very small and unreliable. Obtained LDL, higher than in the case of 60-min incubation time, is still well below the maximum drinking water $\mathrm{UO}_{2}{ }^{2+}$ contamination level defined by the US EPA (130 nmol L $\left.{ }^{-1}\right)$ [27]. It can be concluded that the possibility of adjusting the analytical parameters of proposed sensors to predicted $\mathrm{UO}_{2}{ }^{2+}$ concentration, by changing the sample incubation time, can be very useful for future applications.

The possibility of regeneration of developed biosensors was also tested. However, due to strong interaction between uranyl ion and phosphate moieties of ssDNA, it was not possible to wash out $\mathrm{UO}_{2}{ }^{2+}$ cation from the receptor layer. Accordingly, new ssDNA monolayer has to be prepared before each analysis. However, there is a possibility to precipitate uranyl ion (e.g., with ferrocyanide anion [28]) for regeneration of the receptor layer. This work is currently in progress in our laboratory.

The selectivity of proposed biosensor was examined for incubation time of $5 \mathrm{~min}$, at the concentration of $0.4 \mu \mathrm{mol} \mathrm{L}-1$ for all cations tested. The effect of chosen interfering ions on electrochemical methylene blue signal is shown in Fig. 5. Only for $\mathrm{Pb}^{2+}$ and $\mathrm{Ca}^{2+}$ cations more significant response was observed, although still over twice lower than for $\mathrm{UO}_{2}{ }^{2+}$. The statistical analysis of these results was conducted. Test of statistical significance of the differences of mean responses ( $t$ test) was performed for each cation in comparison to uranyl ion. Analysis of each sample was repeated four times $(n=4)$. In each instance, the mean and the standard deviation were calculated and the subsequent computation was performed to achieve experimental values of $t$ statistics. It can be concluded that the selectivity for all cations was significantly different from uranyl ion results $(\alpha=0.05$, critical value of $t=2.45$; experimental values of $t$ for interfering cations were as follows: $\mathrm{Pb}^{2+}, 8.90 ; \mathrm{Cu}^{2+}, 8.40 ; \mathrm{Ca}^{2+}, 15.58$; $\mathrm{Mg}^{2+}, 15.46$; $\mathrm{Fe}^{3+}, 26.21$; $\mathrm{Cd}^{2+}, 15.26$; and $\left.\mathrm{Sr}^{2+}, 22.00\right)$. There is a possibility that selectivity could be further increased after optimization of immobilized oligonucleotide length, as well as the density of probes on the transducer. Nevertheless, the presented sensor allows for uranyl ion determination in samples without abovementioned interferents.

\section{Conclusions}

It has been shown herein that gold electrodes modified with short-chain ssDNA oligonucleotides can be used for tracelevel voltammetric determination of uranyl cation. According to our knowledge, this is the first report on the use of DNA-modified biosensor for $\mathrm{UO}_{2}{ }^{2+}$ analysis. The proposed ssDNA recognition layer functions via the strong interaction between phosphate DNA backbone and $\mathrm{UO}_{2}{ }^{2+}$ ion. It was found that the usage of redox properties of uranyl cation for generation of analytical signal is impractical; accordingly, external redox marker, namely methylene blue, was employed for electrochemical measurements. Due to the competition between $\mathrm{UO}_{2}{ }^{2+}$ and methylene blue, current signal decreases proportionally to the analyte concentration.

Proposed ssDNA-modified electrodes showed good selectivity towards $\mathrm{UO}_{2}{ }^{2+}$, against some common metal cations. Only $\mathrm{Pb}^{2+}$ and $\mathrm{Ca}^{2+}$ cations showed considerable interfering effect, although the response towards $\mathrm{UO}_{2}{ }^{2+}$ was still over twice higher.

The remarkably low detection limit of $30 \mathrm{nmol} \mathrm{L}^{-1}$ for $\mathrm{UO}_{2}{ }^{2+}$ ions could be achieved by extending the sample incubation time to $60 \mathrm{~min}$. For short sample incubation periods $(5 \mathrm{~min})$, upper detection limit of $1 \mu \mathrm{mol} \mathrm{L}{ }^{-1}$ and lower detection limit of $50 \mathrm{nmol} \mathrm{L}{ }^{-1}$ were registered. The possibility of adjusting the performance of proposed modified electrodes to predicted concentration of $\mathrm{UO}_{2}{ }^{2+}$ in sample solution is of special importance.

Obtained results, while still preliminary, are very promising in the comparison with other $\mathrm{UO}_{2}{ }^{2+}$ sensors, as shown in Table 1. To further improve the working parameters of proposed biosensors, including the elimination of interfering effect from certain cations, efforts are currently in progress to optimize the length and packing density of oligonucleotides used for electrode modification. Moreover, the use of impedance spectroscopy and redox markers other than methylene blue for generation of the analytical signal is also planned.

Acknowledgments This work was co-financed by the Polish Ministry of Science and Higher Education (research project N N204 125237) and Warsaw University of Technology.

Open Access This article is distributed under the terms of the Creative Commons Attribution Noncommercial License which permits any noncommercial use, distribution, and reproduction in any medium, provided the original author(s) and source are credited.

\section{References}

1. Hammond CR (2000) In: Handbook of chemistry and physics, 81 st edn. CRC, Boca Raton

2. Holzbeche J, Ryan DE (1980) Anal Chim Acta 119:405-408 
3. Caddia M, Iversen BS (1998) J Anal At Spectrosc 13:309-313

4. Mlakar M, Branica M (1994) Marine Chem 46:61-66

5. Djogić R, Branica M (1995) Anal Chim Acta 305:159-164

6. Wang J (1985) Stripping analysis: principles, instrumentation and applications. VCH, New York

7. Mlakar M (1993) Anal Chim Acta 276:367-372

8. Kefala G, Economou A, Voulgaropoulos A (2006) Electroanalysis 18:223-230

9. Gholivand MB, Nassab HR, Fazeli H (2005) Talanta 65:62-66

10. Zobel CR, Beer M (1961) J Biophys Biochem Cytol 10:335-346

11. Becker A, Tobias H, Mandler D (2009) Anal Chem 81:8627-8631

12. Banerjeea R, Katsenovichb Y, Lagosb L, Sennc M, Najad M, Balsamoe V, Pannellc KH, Li Ch (2010) Electrochim Acta 55:7897-7902

13. Shervedani RK, Mozaffari SA (2005) Surf Coat Tech 198:123-128

14. Moody GJ, Slater JM, Thomast JDR (1988) Analyst 113:699-703

15. Wojciechowski K, Wróblewski W, Przygórzewska J, Rokicki G, Brzózka Z (2002) Chem Anal 47:335-346

16. Ellington AD, Szostak JW (1990) Nature 346:818-822

17. Hianik T, Wang J (2009) Electroanalysis 21:1223-1235
18. Dolatabadi JEN, Mashinchian O, Ayoubi B, Jamali AA, Mobed A, Losic D, Omidi Y, de la Guardia M (2011) TRAC-Trend Anal Chem 30(3):459-472

19. Brown AK, Liu J, He Y, Lu Y (2009) Chembiochem 10:486-492

20. Lee JH, Wang Z, Liu J, Lu YJ (2008) J Am Chem Soc 130:14217-14226

21. Privett BJ, Shin JH, Schoenfisch MH (2010) Anal Chem 12:4723-4741

22. Ziółkowski R, Górski Ł, Zaborowski M, Malinowska E (2010) Bioelectrochemistry 80:31-37

23. Camillone N (2004) Langmuir 20:1199-1206

24. Talib ZA, Baba Z, Kurosawa S, Sidek HAA, Kassimb A, Yunus WMM (2006) Am J Appl Sci 3:1853-1858

25. Yazzie M, Gamble SL, Civitello ER, Stearns DM (2003) Chem Res Toxicol 16:524-530

26. Cohen AS, Terabe S, Smith JA, Karger BL (1987) Anal Chem 59:1021-1027

27. United States Environmental Protection Agency. Available at http://www.epa.gov. Accessed 5 July 2011

28. Haba FR, Wilson CL (1963) Microchim Acta 51:305-312 